\title{
ESTUDO DOS MECANISMOS DE ESCRITA EM ADOLESCENTES PSICÓTICOS ${ }^{1}$
}

\author{
Laurent Combres ${ }^{2}$ \\ Université Toulouse II - Le Mirail - Toulouse - France
}

\begin{abstract}
Estudamos os mecanismos das práticas de escrita, especificamente, a dos adolescentes psicóticos. Uma prática clínica em ateliê (de escrita) mostra que escrever pode tratar a doença mental, considerando-a uma falta de inscrição social do sujeito. Nossa hipótese articula a palavra e o escrito como os reflexos da inscrição do sujeito na linguagem e a inscrição social como uma função especial dos mecanismos da linguagem.
\end{abstract}

Descritores: Psicose. Escrita. Linguagem escrita. Adolescentes.

\section{Dispositivo}

Apermitiu o acolhimento de adolescentes que, na sua maioria, foram diagnosticados como psicóticos, para o estudo de seus mecanismos de escrita.

Instalado num lugar especialmente reservado para isso e sem a exigência de assiduidade por parte dos participantes, durante dois anos, recebemos os escritos daqueles aos quais essa oferta teria, ao menos, suscitado algum interesse. Anteriormente à distribuição de um caderno por participante, no qual simplesmente se sugeria que escrevesse seu nome, sempre apre-

1 Tradução: Helena M. S. Bicalho. Docente do Instituto de Psicologia-USP.

2 Doutorando da Université de Toulouse II, Le Mirail, L’Unité de Formation et Recherche. Endereço para correspondência: Université de Toulouse - Le Mirail (Toulouse II), 56, allée Antonio Machado, Toulouse, France, 31058. Endereço Eletrônico: lcombres@club-internet.fr 


\section{Laurent Combres}

sentávamos a cada um as condições desse trabalho. Este foi conduzido no enquadre de uma pesquisa para uma tese, sem outras instruções nem recomendações e, com esse dispositivo elementar, cada adolescente era liberado, em seguida, para escrever ou não, participar ou não do ateliê.

Tal dispositivo técnico que se desejaria estar referenciado à teoria psicanalítica, poderia ser percebido como contraditório à Psicanálise, na medida que ela é um "banco de ensaio" falado. Uma abordagem da Psicanálise, desde os trabalhos de Sigmund Freud e de Jacques Lacan, mostra que ambos, antes de tudo, questionaram a fala; o principal interesse do trabalho, no ateliê de escrita, no entanto, foi notar a existência ou não do escrito e compreender seus mecanismos. Para validar o interesse psicanalítico dessa pesquisa, lembremos aqui um ponto de trabalho de releitura, do caso do Presidente Schreber, por Sigmund Freud e Jacques Lacan. Abordar o trabalho de Daniel Paul Schreber, que publicou a relação dos fenômenos psicóticos dos quais foi vítima, necessitou de dois princípios: o primeiro, que nos interessa, colocou o texto de Schreber como retranscrição de um discurso da psicose. O segundo princípio, por intermédio de um trabalho de interpretação desse texto autobiográfico, permitiu tomar conhecimento dos mecanismos em jogo na psicose paranóica. Assim, tanto a psicanálise freudiana quanto a lacaniana destacaram a compreensão dos mecanismos de linguagem pelo estudo da fala e quanto a escrita fez parte disso, desde o início das elaborações teóricas psicanalíticas sobre a psicose.

Tal como queríamos engajá-lo, o trabalho apóia-se sobre os escritos dos sujeitos que vêm ao ateliê. No entanto, a fala não estaria, de qualquer maneira, excluída, ao contrário. Constatar que um dito venha, talvez, modificar o escrito, assim como o contrário, permite destacar suas correlações; esse estudo encontrou a fala, ela é, de início, alcançada sobre o escrito.

\section{Escrita e grupo}

Nem todos os adolescentes que participaram no enquadre desse dispositivo de escrita, forçosamente, escreveram. A maneira como ela foi feita - 
aceitar, ou não, responder a essa oferta de escrita - não significou, caso um dentre eles não escrevesse, que sua escrita não existiria. Com efeito, recusar escrever e não escrever se manifestam, unicamente, pela ausência do escrito e não permitem uma distinção confiável entre a negação e a impossibilidade. Se a foraclusão, própria à psicose, se distingue da inibição neurótica, uma e outra são, no entanto, manifestações da existência do sujeito do inconsciente. Mas tudo isso não significa que o sujeito não esteja concernido pela escrita. No mínimo, isso supõe que o inconsciente, a escrita e o sujeito estão ligados de qualquer maneira, sem, todavia, garantir que ele escreva qualquer coisa.

Estudamos, nesse trabalho, somente os casos nos quais esses adolescentes aceitaram escrever.

Uma vez atravessada essa fronteira de uma passagem ao escrito que, freqüentemente, na neurose, significa o apagamento de si em proveito do escrito e pode, então, produzir a escrita insuportável para um sujeito neurótico, nos participantes deste ateliê houve um engajamento num trabalho regular. Sem tirar conclusões muito prematuras, notemos que aqueles que consentem em escrever já estão ligados, sob o registro da psicose, ao dispositivo institucional.

Em geral, aqueles que escreveram, sempre começaram por uma prática de escrita que pareciam ter em comum. Sem dúvida, era assim porque já existia um trabalho de "secretariado" da atividade deles, dirigida por um educador da instituição. Se isso confirmasse que uma instituição pode pretender ditar a inscrição de um sujeito no laço social, não seria bem-vindo de nossa parte avançar sem colocar a questão da instituição e do que adquire valor de norma. Tal como Sigmund Freud descreveu no capítulo VIII, "Estados amorosos e hipnose”, do texto Psicologia das massas e análise do eu (Freud, 1921/1968), a organização grupal se faz por intermédio de um pólo, que organiza um comportamento conforme e idêntico aos indivíduos entre eles. Se isso explicaria que pode existir uma escrita-tipo, padrão, pelo contrário, isso não nos diz se tal organização grupal é observável para a especificidade dos casos de psicose, e nem explica que possa surgir, em seguida, uma escrita particular para alguns, pois esse fenômeno se produz muitas 


\section{Laurent Combres}

vezes. Sobre esse segundo ponto, o seminário A identificação, de Jacques Lacan (Lacan, 1996/1961-1962), nos permitirá precisar como uma manifestação torna-se particular ao sujeito. Nesse seminário, Jacques Lacan destaca no sujeito um traço, o traço unário, que é a condição mínima para que seja possível e desejável sua estruturação. É somente após a existência desse traço unário que se determina a estrutura, segundo seja possível, ou não, a fonação do traço unário e a escrita, ou não,daquilo que é assim fonetizado. Portanto, o sintoma tal como nós o conhecemos, a arte, o nome próprio, são, por intermédio da estrutura, os modos de expressão dessa particularidade do sujeito, que não se dissolve no grupo. Ao contrário, eles assinalam sua préexistência e sua resistência ao grupo e a esses mecanismos identificatórios. Dito isso, duas questões sobre as quais retornamos ficam, então, em suspense: como se pode explicar que haja uma, e até várias respostas, a essa oferta de escrita?Quais são as condições de existência do que seria essa escrita de um grupo de psicóticos?

Se o trabalho começar por uma escrita adaptativa, nós não colocamos em causa o trabalho ocorrido na instituição, onde pôde ser criado esse ateliê de escrita, pois esse trabalho não seria possível sem a reflexão da equipe de tratamento. Ao se perguntar se o perigo nas aprendizagens não estaria, justamente, sobre a vertente de uma identificação imaginária que poderia exigir uma instituição de tratamento, a equipe colocou os fundamentos de uma posição que pudesse reconhecer a singularidade de cada um. Se isso ocorreria, talvez, ao preço de dever suportar os transbordamentos, que eram a expressão dessa singularidade, em quase todos os casos eles se apaziguavam, porque os sujeitos podiam estar certos de que suas reinvidicações seriam ouvidas. Na instituição, fazer ou não fazer laço social, não queria dizer ser ou não ser sujeito. No ateliê de escrita, escrever, para esses sujeitos, poderia resgatar uma tentativa de criação ou de recriação do laço social. 


\section{A particularidade psicótica.}

Poucos jovens superaram a difícil etapa dessa escrita de grupo e, mesmo uma vez superada, alguns, freqüentemente, aí retornavam. Portanto, os textos têm, num momento ou em outro, mudado radicalmente, como as palavras que os acompanham. Havia ali, então, verdadeiramente, uma questão de escrita, ela lhe pertencia estritamente; e se verificava a ligação entre escrito e fala.

Os adolescentes que consentiram nessa mudança de estilo, investiram, desde então, de uma outra maneira, no lugar institucional deles, e isso sem se remeterem exclusivamente ao dispositivo proposto e discutido pela equipe de tratamento da instituição. Se nos colocamos nesse trabalho, após o escrito do grupo, poderíamos ter uma leitura do que o sujeito é no laço social: verificamos, então, que um trabalho sobre o escrito poderia ter uma incidência sobre a inscrição social do sujeito escritor; uma articulação entre escrito, escrita, língua e fala seria, então, verificada.

Para distingui-los dos escritos precedentes, todo texto que no começo era escrito, no enquadre do ateliê, teria como único traço distintivo o nome daquele que o comporia. Cada um desses textos eram, assim, a retranscrição sistemática e semelhantes aos feitos e gestos do portador do nome escrito sobre a capa dos cadernos. Nesse segundo tempo, o dos escritos particulares, o estilo empregado seria suficiente, quando a ocasião se apresentasse. Para reconhecer o seu autor, para compreender esse mecanismo e distingui-lo daquele dos primeiros escritos, é preciso examinar se o nome articulou suas produções, e, caso contrário, como podem ser compostos.

Em referência à teoria psicanalítica, na medida que se faça do nome próprio a marca fundamental do sujeito, em uma ou várias línguas, toda outra observação de uma manifestação de um sinal característico deve ser comparável ao nome próprio, ambos deduzidos da função do traço unário. Pelo contrário, a questão fica aberta, quando alguém se demanda como, lá onde não é ou não pode ser colocada essa função, ou seja, nos casos de psicose, observa-se assim mesmo uma manifestação da particularidade do su- 


\section{Laurent Combres}

jeito; ela permite diferenciar, entre os autores dos escritos, como o nome distinguiria seus textos atuais dos primeiros, construídos em uníssono. Em relação à psicose, é a fonação do traço unário que não se faz; a escrita do que é fonetizado do traço unário - e que se escreve, preferencialmente, sob a forma do nome-, é, então, impossível. Esses escritos particulares existiam sem o suporte distintivo do nome escrito, sem a colocação em função dessa articulação entre o traço unário e o nome próprio e sem a orientação induzida pelo dispositivo de tratamento, tal como existia nessa instituição.

Antes de avançar na compreensão desses mecanismos, devemos retornar a uma questão deixada em suspense, ou seja, a existência dessa escrita de grupo, adaptada a um modelo, constituída por esses sujeitos de estrutura psicótica.

Se for confirmado que a psicose paranóica pode encontrar sua estabilização por uma identificação imaginária ao desejo do Outro, o interesse que uma instituição de tratamento se preocupe com o que pode ser seu desejo, enquanto instituição, pode assegurar, até autorizar, uma tal estabilização psicótica, e explicar assim, a existência dos textos escritos em uníssono. Certamente, nós assimilamos, nesse caso, o desejo de uma instituição ao desejo do Outro do sujeito. Mas uma instituição de tratamento tem, entre outros objetivos, proteger o sujeito contra si mesmo, intervindo nessa dialética do sujeito e do Outro. A possibilidade desses suportes institucionais, cuja prática do escrito em grupo favorece tais estabilizações, deve, então, necessitar uma reflexão aprofundada, tendo ao menos que provar que a função da escrita concerne todo sujeito. Dito isso, não encontramos, entre os sujeitos psicóticos, somente os paranóicos. A esquizofrenia como a melancolia aí estão também representadas. Ora, em relação a esses casos de psicose, e após os trabalhos de Sigmund Freud e Jacques Lacan, a identificação ao desejo do Outro não é uma das primeiras vozes de estabilização nem de suplência.

Se, a priori, devemos deixar essa questão em suspense pelo menos porque, para fundá-la, seria necessário estudar, em detalhe, as organizações sociais das instituições de tratamento acolhem os sujeitos de estrutura psicó- 
tica, assim como fazer um estudo empírico em grande escala, levando em conta as diferentes psicoses, nesse trabalho, privilegiamos o estudo sobre o que cada sujeito escreveu.

Uma tal compreensão de cada caso não poderia ser possível pela análise dos traços característicos de um grande número de indivíduos, submetidos a tal experiência. No melhor dos casos, assinalam a existência das operações psíquicas constitutivas do grupo e permitem uma prática do escrito, e que isso não é sem conseqüência para a constituição de um laço social. Isso dito, e para retornar ao nosso trabalho, se não se suprime assim o estilo (singularidade) e a forma (grupo), se produz, então, um encontro entre esse escrito, necessário ao laço social do grupo, em referência ao escrito do grupo, e essa identidade mínima que é um sujeito em referência ao traço unário. Para as psicoses, o escrito do grupo é o escrito do portador do nome que reconhece a instituição mas não aprofundou esse paradoxo: há escritos particulares, apesar da existência impossível do escrito do nome após o traço unário, como já evocado. É, portanto, nessa diferença entre forma e estilo, que tentamos explicar como puderam ser escritos textos tão distintos que o nome permitia diferenciar, entre eles, os escritos de grupo, sem que eles fossem, nem uns nem outros, uma escrita dessa fonação impossível do traço unário na psicose.

\section{Um mecanismo de escrita}

Até aqui, abordamos a psicose como uma falha na passagem do traço unário à fala. Nesse caso, o que se escreve não pode ser o exercício da função do traço unário. Isso supõe que esses segundos escritos foram produzidos através de um outro mecanismo. Mas não detalhamos esse mecanismo, a não ser por essa distinção entre forma e estilo. É preciso, portanto, estudar mais profundamente esse mecanismo de escrita de modo que seja possível compreender a transposição, por parte de cada um dos sujeitos, da dimensão grupal da escrita. 


\section{Laurent Combres}

Tendo sempre como referência o seminário inédito, A identificação, onde o estudo da escrita prefigura o da fala, Jacques Lacan propôs como hipótese funcional para a compreensão da estrutura psíquica e suas manifestações, uma triangulação entre sujeito, linguagem e real. O traço unário, ligando sujeito e linguagem, ao qual nos referimos até agora, não é o único elo que coloca em movimento uma função de escrita. Se, portanto, não é a mesma escrita, e há um elo ligando linguagem e real, distinto do sujeito, que é a própria escrita: o conjunto das letras, dos traços, de toda marca que está escrita, independentemente do sentido que se pode dar à escrita. Segundo essa aproximação, colocada por Jacques Lacan, essa escrita existe sem a intervenção do sujeito e faz sentido como escrita, unicamente, quando o sujeito aí se coloca para escrever. Para ilustrar essa hipótese, um artigo, um livro, uma gravura, existem somente quando lhes é dado o seu nome de artigo, de livro ou de gravura. Pode-se, assim, fazer existir a escrita antes que lhe seja dada seu sentido de escrita.

A estrutura psicótica não impediu a alguns desses sujeitos de escrever e de encontrar, por essa escrita, o que nós comparamos à função do traço unário, próprio à neurose, quando sua função está em exercício. Dessa maneira, esses sujeitos ao menos se serviram dessa escrita, desse nó, ligando linguagem e real.

Portanto, isso não explica ainda, completamente, porque esses escritos podem ser particulares a cada um dos sujeitos que escreveram. Como tal, esse nó é independente do sujeito, e nada indica que seja único, do mesmo modo que o traço unário. Da mesma forma como o que ocorre na neurose, a fala pronunciada, desde a incidência do traço unário, pode ser uma manifestação da particularidade do sujeito, assim também uma escrita que se manifesta só, e sem a intervenção do traço unário, como particularidade do sujeito, não pode, por sua vez, ser particular. Mas, por esse procedimento que queremos detalhar, qualquer coisa introduz a particularidade subjetiva.

Assim que eles atravessaram a fronteira da escrita do grupo, ou seja, desde que o escrito veio se manifestar como se tivesse sido independente deles, todos fizeram, oralmente, um comentário do que acabava de ser escri- 
to; o que disseram de seus novos escritos seria conectado a uma significação estrutural, própria às diferentes psicoses, pois, para todos, foi esse momento em que pôde ser colocado com precisão o diagnóstico de estrutura. Além disso, quando os escritos desses sujeitos se modificaram, o modo deles fazerem inscrição social, no interior da instituição, mudou também, demonstrando que uma prática particular do escrito poderia ter conseqüências sobre a inscrição social do sujeito. Esses propósitos - suas falas sobre seus escritos não apenas atribuíam um sentido às suas produções escritas, mas permitiram também sustentar, no espaço que durou o trabalho, o que se escrevia. Por exemplo, enquanto um deles, no fim de cinco meses, passados em retranscrever o conjunto desses feitos e gestos, começou um trabalho escrito sobre sua genealogia: seu laço social matizado de violências e provocações. Desde então, esse laço social apaziguou-se visivelmente, enquanto que ele se tornaria, paralelamente, ator de seu lugar. Para um outro, uma figuração pelo desenho de uma representação do corpo provocou oposições verbais que ele pôde dirigir aos seus companheiros, enquanto esses gozavam da posição masoquista que ele ocupara até então. Para um outro, ainda, uma outra prática de escrito veio fechar a rede de significantes na qual ele se lia, enquanto que, pela primeira vez, ele manifestara o desejo de orientar diferentemente seu lugar.

Assim, para todos eles, que atravessaram a dimensão de uma escrita de grupo para uma escrita particular, a mudança do escrito, em sua prática, é acompanhada de uma modificação de sua inscrição social, ao menos na instituição. Nós resumimos, assim, esse mecanismo da saída: um escrito se manifesta sem o artifício de um suporte construído sobre a função do nome. Dizer qualquer coisa traz sempre uma significação. Escrita e significação conotam o conjunto deles de uma particularidade irredutível a qualquer outro discurso, qualquer outro saber ou dispositivo. Esta prática do escrito participa da orientação pelo sujeito de sua inscrição social. 


\section{Considerações finais}

Para concluir, devemos retornar sobre esta segunda questão deixada em suspenso, ou seja, o fato de que tenha havido uma, ou até várias respostas, a esta oferta de escrita. Com efeito, é preciso dizer a cada um dos sujeitos que responderam a esta oferta de escrita, que esse trabalho ocorreria no âmbito de uma pesquisa para uma tese e que seus textos poderiam ser lidos e comentados por outros. Dito de outra maneira, é possível que isso tenha podido favorecer os efeitos das práticas do escrito que nós estudamos. Teoricamente, tal explicação se funda sobre os trabalhos de Sigmund Freud e Jacques Lacan, que, em seus comentários de textos de sujeitos psicóticos Daniel Paul Schreber e James Joyce - destacaram como o reconhecimento pelos outros fez parte do trabalho desses dois grandes psicóticos. Daniel Paul Schreber esperava, na publicação das Memórias de um neuropata (Schreber), que as autoridades competentes pudessem vir verificar sobre seu corpo as vicissitudes que ele teria atravessado; James Joyce queria que seu trabalho chamasse a atenção dos universitários, durante mais de trezentos anos. Ambos tinham um objetivo: o primeiro, abrir pelo seu escrito uma via de estabilizações temporária de sua psicose que estava desencadeada; o segundo, colocar uma suplência, evitando assim o desencadeamento psicótico. No entanto, Daniel Paul Schreber como James Joyce, ambos de um nível intelectual elevado, escolheram a quem endereçar seus textos. Se a constitui ção e a existência de um endereçamento oferece, assim, a possibilidade que o escrito encontre um interesse para as psicoses desencadeadas, como para aquelas que não são, nada garantiria que os textos desses adolescentes psicóticos seriam retomados na elaboração de nossa pesquisa. Além disso, nenhum deles manifestou, claramente, se o enquadre implícito a esse trabalho constituiu para ele um endereçamento, e ninguém quis saber o que foi feito de seus escritos. Mas nessa eventualidade é, então, possível que essa experiência lhes tenha impulsionado a escrever. 


\title{
Estudo dos Mecanismos de Escrita em Adolescentes Psicóticos
}

Combres, L. (2005). Study of writings practices of psychotics teenagers. Psicologia USP, 16(4), 57-68.

\begin{abstract}
We study psychological mechanisms of writings practices especially in the cases of psychotics teenagers. A clinical practice in a writing work-group shows that writing is a treatment of mental illness considering as a dysfunction of social inscription. Our hypothesis articulate speech and written work as reflections of the subject's inscription in language, and social inscription as special work of linguistic mechanisms.
\end{abstract}

Index terms: Psychosis. Handwriting. Written language. Adolescents.

Combres, L. (2005). Etude dês mécanismes d'écriture dans lês cãs de psychose chez ládolescent. Psicologia USP, 16(4), 57-68.

Résumé: Nous étudions les mécanismes des pratiques de l'écriture spécifiquement dans les cas de psychose chez les adolescents. Une pratique clinique em atelier (d'écriture) démontre qu'une écriture participe au traitement de la maladie mentale considérée comme dysfonctionnement de l'inscription sociale du sujet. L'hypothèse que nous avançons articule parole et écrit comme reflets de l'inscription du sujet dans le langage, et l'inscription sociale comme fonction particulière des mécanismes langagiers.

Mots clésfs: Psychose. Écriture. Langage écrit. Adolescents.

\section{Referências}

Freud, S. (1968). Psychologie collective et analyse du moi. Paris: Payot. (Trabalho original publicado em 1921)

Lacan, J. (1996). L’identification. Paris: Association Freudienne Internationale. (Trabalho original publicado em 1961-1962) 


\section{Laurent Combres}

\section{Referências Consultadas}

Bon, F. (2000). Tous les mots sont adultes. Paris: Fayard.

Bonniface, C. (1992). Les ateliers d'écriture. Paris: Retz.

Cadoux, B. (1999). Escritures de la psychose. Paris: Aubier.

Foucault, M. (1973). Moi, Pierre Rivière, ayant égorgé ma mère, ma soeur et mon frère... Un cas de parricide au XIXème siècle présenté par Michel Foucault. Paris: Gallimard.

Freud, S. (1905). Cinq Psychanalyses. Paris: Presses Universitaires de France.

Freud, S. (1981). Essais de psychanalyse. Paris: Payot. (Trabalho original publicado em 1921)

Freud, S. (1967). L'interprétation des rêves. Paris: Presse Universitaires de France. (Trabalho original publicado em 1899)

Freud, S. (1965). Totem et tabou. Paris: Payot. (Trabalho original publicado em 1912).

Freud, S. (1992). Malaise dans la civilization. Paris: Presses Universitaires de France. (Trabalho original publicado em 1929)

Gelb, I.-J. (1988). Pour une théorie de l'écriture Paris: Flammarion. (Trabalho original publicado em 1952)

Lacan, J. (1975-1976). Le séminaire. Livre 23: Le sinthome. Inédit.

Lacan, J. (1981). Le séminaire. Livre 3: Les psychoses. Paris: Seuil. (Trabalho original publicado em 1955-1956)

Pommier, G. (1993). Naissance et renaissance de l'écriture. Paris: Presses Universitaires de France.

Soler, C. (2001). L'aventure littéraire ou la psychose inspirée. Paris: Edition du Champ Lacanien.

Schreber, D. P. (1975). Mémoires d'un névropathe. Paris: Seuil. (Trabalho original publicado em 1903)

Recebido em: 25.05.2005

Revisto e encaminhado em: 01.08.2005

Aceito em: 29.08.2005 